\title{
A Probabilistic Shortage of Private Land Opened to Hunters in Northwest Minnesota
}

\author{
Rutherford Card Johnson ${ }^{1,2 *}$, Eddie Walker II ${ }^{1}$ \\ ${ }^{1}$ University of Minnesota Crookston, Crookston, MN, USA \\ ${ }^{2}$ Harvard University Extension School, Cambridge, MA, USA \\ Email: *ruj579@g.harvard.edu, walke810@crk.umn.edu
}

How to cite this paper: Johnson, R.C. and Walker II, E. (2018) A Probabilistic Shortage of Private Land Opened to Hunters in Northwest Minnesota. Modern Economy, 9, 213-240.

https://doi.org/10.4236/me.2018.91014

Received: December 28, 2017

Accepted: January 22, 2018

Published: January 25, 2018

Copyright ( 92018 by authors and Scientific Research Publishing Inc. This work is licensed under the Creative Commons Attribution International License (CC BY 4.0).

http://creativecommons.org/licenses/by/4.0/

(c) (i) Open Access

\begin{abstract}
Outdoor recreation in Northwest Minnesota is popular year round, and many residents and visitors participate in activities such as hunting, fishing, snowmobiling, boating, and much more. Land available for hunting, however, is at a particular premium. Hunters overall do not appear to have enough land on which to hunt as they compete with both other hunters and state regulations. Some private land owners have land that they keep for their own hunting purposes, and some of that land is kept exclusively for hunting. Private landowners in NWMN have consistently demonstrated an unwillingness to open their land to outside consumptive recreational uses, such as hunting, even for a fee. This situation may leads to potential overuse of some land with respect to hunting, while other land is potentially underused, creating a potential "tragedy of the anticommons". Meanwhile, hotels and resorts in the region are engaged in the ever-growing worldwide trend of ecotourism and agritourism, though they have relatively few arrangements with private land owners. In this study, a probabilistic demand approach is used to analyze strategic interaction between land owners and hunters based on the results of three surveys conducted for the State of Minnesota and the Economic Development Administration (EDA). Mechanisms to create an outcome that aligns the utility maximization strategies of land owners and hunters are suggested.
\end{abstract}

\section{Keywords}

Probabilistic Demand, Land Use, Incentives, Decision Strategy, Behavioural Economics

\section{Introduction}

Looking over the vast fields of Minnesota, one could be forgiven for forgetting 
that land is a scarce resource. Northwest Minnesota (NWMN) is abundant in land and is one of the world's leading growers of sugar beets, among many other crops. Outdoor recreation is popular year round, and many residents and visitors participate in activities such as hunting, fishing, snowmobiling, boating, and much more. Hunting is particularly popular. For example, in 2016, the total deer harvest was 173,213 (down from around a decade earlier, which reached around $225,000)^{1}$.

Hunting land, however, is at a particular premium. The Minnesota Department of Natural Resources has indicated that finding suitable land on which to hunt can be difficult. Minnesota is, compared to many other states, rich in public land. Around seventy-five percent of land in Minnesota, however, is privatelyowned, and most hunting takes place on private land ${ }^{2}$. The Minnesota Department of Natural Resources also acknowledges the tension between private land owners and hunters. They indicated that private land becomes closed to hunting when the lack of understanding of the landowners' situation and viewpoints. Land owners have many reasons for which they do not want their land opened

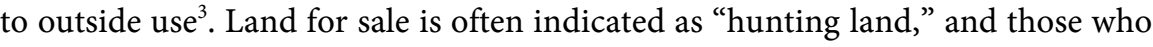
purchase it, despite the significant role they play in wildlife management, may not want outside parties to hunt on their land, despite the benefit that could have to wildlife and natural resource management $[1]^{4}$.

Wildlife is inherently both a scarce resource and a common resource. As a common resource, it is regulated by the state through legislation and hunting licenses. More land equates to more potential wildlife, within one's statutory annual limit, and less competition from other hunters. Hunters do not appear to have enough land on which to hunt as they compete with both other hunters and state regulations. Some private land owners have land that they keep for their own hunting purposes, and some of that land is kept exclusively for hunting. This leads to some land potentially being overused with respect to hunting, while other land is potentially underused, creating a potential "tragedy of the anticommons" [2]. Despite the potential for additional revenue and a more efficient allocation of resources, anecdotal evidence has suggested that private landowners in NWMN have consistently demonstrated an unwillingness to open their land to outside consumptive recreational uses, such as hunting, even for a fee.

Meanwhile, hotels and resorts in the region are engaged in the ever-growing worldwide trend of ecotourism and agritourism. Survey evidence suggests, however, that they have very few arrangements with private land owners. There is a great divide in the number of commercial arrangements between hospitality operations and private land owners and the number of such arrangements that 1"2016 Minnesota Deer Harvest Report.” Minnesota Department of Natural Resources. 25 April 2017.

2“Hunting Land Locations." Minnesota Department of Natural Resources. Retrieved 8 January 2018. http://www.dnr.state.mn.us/hunting/tips/locations.html

3“Hunting private land...it's a privilege." Minnesota Department of Natural Resources. Retrieved 8 January 2018. http://www.dnr.state.mn.us/hunting/privateland/index.html

4“QDMA's Whitetail Report 2016.” Quality Deer Management Association. 
the hospitality operations would like to have. That suggests a definite market potential, but the interest in doing so appears to be rather one-sided. Were land owners to be induced to participate, however, such hospitality operations could potentially serve as an effective manager of the private land's use by outside parties, thereby address some of the concerns private land owners have expressed.

This study uses the results of three surveys conducted for the State of Minnesota and the Economic Development Administration (EDA). The first asked private land owners in NWMN about their current land use and their willingness to accept compensation for opening land to outside parties for recreational purposes, including hunting. The second survey asked hospitality operations in NWMN about their current agritourism and ecotourism operations and their interest in expanding such recreational opportunities for their guests. This third survey was administered to hospitality operations in the region and asked questions pertaining current levels of ecotourism and agritourism offerings to their guests and their interest in expanding, including through collaborations with local land owners. The results of the surveys together show a shortage of land made available for hunting to outside parties has resulted due in part to private ownership and the preferences of private owners. A potential opportunity exists to meet the demand of hunters for land by using hotels and resorts in the region that are engaged in agritourism and ecotourism. Such an outcome may be able to align the utility maximization strategies of land owners and hunters, thereby increasing economic efficiency.

\section{Background}

Private owners can potentially increase efficiency through opening land, either pro bono or for a fee, to outside hunters [3]. However, decision strategies of land owners may be biased against opening land to outside use. As owners of property, they have the right to exclude [4]. Their decision strategies may be influenced by factors beyond price, such as psychological factors and the interaction with information and other land owners [5]. When two parties to a potential contract, i.e., the supply side and the demand side, differ sufficiently in terms of decision strategy, it is possible that a sub-optimal allocation of resources will result due to a misalignment of incentives. Redistribution of use of a particular parcel of land, for example, may yield gains for some while also imposing costs asymmetrically [6]. Such a misalignment can also contribute to social costs [7]. However, if the costs imposed in the situation of denying land use to outside hunters are justified by the benefits otherwise realize by the private ownership of the land, then the incentive to improve the situation for hunters is reduced, for it comes into direct conflict with the real or perceived benefits to land owners [8].

One such cost that could be imposed on private land owners opening their land to outside parties is a loss of intangible value of the land as perceived by its owner. This is similar to the way in which agricultural land bought en masse by outside investors may damage society through damage to the family farm, which 
has intrinsic and indispensable value [9]. That is, private land owners may perceive use of their land by outside parties will change the nature of their land and its use in ways that may not be seen by outside observers. Although it is possible that a decision by a private land owner to open land or not to open land to outside parties is driven entirely by financial considerations, such decisions typically involve other factors that are not directly economic [3]. Thus, the decision strategies of private land owners and of hunters who wish to use private land may quite easily yield different levels of available acreage. Since hunters are left with less available land relative to their quantity of land demanded, a sub-optimal allocation of land use results.

\section{Survey Data}

The primary survey instrument was designed to collect data from private land owners on their willingness to accept compensation (WTA) for opening their private land to outside parties for various recreational purposes. This study focuses on the specific consumptive use of hunting due to the high prevalence of hunting in the region and due to the fact that hunting requires tracts of land both of sufficient size and wildlife content, and there can easily be a scenario in which demand for land exceeds willing supply. Respondents were asked questions regarding their current use of their land, extending beyond recreation into agricultural use, timber, real estate investment, family purposes, mining, and participation in agri/ecotourism. Then a series of questions were asked regarding whether or not the land owner is willing to open land (for a fee or not) to outside parties for various recreational uses, including hunting. Follow-up questions were asked based on previous answers. For example, a respondent that does not want to open land was asked to specify reasons why, and a respondent that is willing to open land is asked to specify the various uses that would be allowed. Quantitative questions regarding acreage currently opened or that would be willing to be opened were included. Valuation questions were included to attempt to determine the land owner's WTA for opening land. An additional survey was administered to NWMN residents and non-residents from elsewhere in the US and Canada to determine willingness to pay for various recreational activities, including hunting.

\section{A Land Use Model of Parallel Rationality}

The shortage of land in NWMN available for use by outside hunters may be a one-sided problem. Land owners may not perceive the benefits of opening land to outside hunters to exceed the costs, even though the decision not to open imposes a cost or penalty on the hunters. Opening land to outside use has inherent risks, many of which were identified by the land owner respondents to the survey, e.g., liability risks. However, entrepreneurial use of land in terms of seeking additional rents through opening the land to outside parties has little or no risk premium. Wealthier land owners and land owners who receive sufficient income 
from other uses of their land are much more likely to be risk averse with respect to opening their land to outside use [10].

Additionally, in terms of strategic interaction between the land owners and outside parties, the "power distribution" is inherently unequal. The land owners, being the owners, have all the power over the use of their land, within the law, and have the sole right to decide whether to open that land to outside parties [11]. In the presence of such an asymmetrical power distribution, the payoff matrix for each side may be such that compromise between land owners and outside parties over land use is not a stable equilibrium (Carrillo and Palfrey, 2009). Put another way, land owners do not have to open their land. They have the right to exclude. Their decision is based on their own strategy and does not typically internalize costs and/or penalties borne by the hunters. That friction contributes to the potential sub-optimal allocation of private land opened for recreational use relative to the demand for such land by outside parties and therefore should be kept in mind when considering programmes or incentives to induce land owners to open their land. However, the asymmetry in power distribution may have a positive impact in that, should incentives cause the paradigm shift in favour of opening land to outside use, peer-induced fairness may induce some land owners to be fair in distribution of land access among outside users rather than instituting price discrimination or similar policies (Ho and $\mathrm{Su}, 2009$ ).

The surveys support anecdotal evidence attained before the said surveys were given and suggests that land owners and hunters have different decision strategies such that the optimal outcome for one is statistically different from the optimal outcome of the other. Drawing from probabilistic demand, a Choice Wave, then, may be used to model both groups as two separate consumer types. Choice Waves are mathematically orthogonal in an n-dimensional Hilbert space and represent non-interacting decision strategies yielding statistically different outcomes in expectation value [12] [13]. Each Choice Wave represents its own noninteracting, parallel economic "world," each with its own decision strategy and its own rationality distinct from those in other "worlds." In that framework of economic parallel rationality, the classical economic man still exists, yet there is an infinite number of different versions in an infinite number of parallel economic worlds in hyperspace.

In the land use scenario of the present study, there are two worlds: land owners and hunters. There is "Economic Man-Land Owner" and "Economic ManHunter." However, since in this case that division does not represent two different groups of consumers, but rather two sides to a potential transaction, the Choice Waves do not represent different segmentations of a market, but two distinct stakeholders in the land use decision. That is, the stakeholders in the land use decision exist within two parallel rational economic worlds. If the decision strategy of each parallel state of rationality results in a utility maximizing land use allocation significantly different from the utility maximizing choice other stakeholders, then there is a misalignment of incentives, and an inefficient allocation of land and sub-optimal outcomes may quite likely result. That is, if land 
owners and hunters have significantly different utility maximizing levels of use of private land for hunting by outside parties, then the incentives of land owners and hunters are misaligned, and a sub-optimal allocation of private land for outside use may result. However, even in such a case of sub-optimal allocation of land for hunting, the distribution of burden is borne asymmetrically due to the asymmetrical power distribution, i.e., the private land owners have all the power relative to the hunters regarding how they use their land. Land owners can easily choose their utility maximizing level of land allocation for hunting by outside parties, and the optimal level of land desired by the hunters need not be achieved in order for the land owners to maximize utility. That utility maximizing choice by the land owners may impose an externality in the form of overuse of other available land by hunters; crowding of hunters, creating potentially dangerous situations; and wildlife management issues.

Under the assumption that there exists a goal of inducing more private land owners to open their land to outside parties for hunting, then it is necessary to establish a "bridge" that can span the two economic worlds and align their incentives, creating a more efficient allocation of resources and a more optimal allocation of land use. Certain mechanisms and/or institutions may be able to serve as a bridge between two different groups, better align incentives, and promote a more efficient allocation of resources [14].

In the absence of strong institutions or mechanism that facilitate land use transactions between private land owners and outside parties, there is likely to be a lack of commitment by both sides [15]. The public may see little incentive to use a particular parcel of land, other things being equal, instead continuing to use land that may be overused or overcrowded. Hunters seek land on which to hunt, and the ownership of specific piece of equivalent land is irrelevant unless said ownership imposes costs on the hunter. Land owners similarly feel little commitment to the public in terms of providing land for hunting, which may simply indicate preferences. It also may be a form of response to the lack of commitment by the public, i.e., the hunters simply want suitable land for hunting, so land owners may assume that if they do not open their land to outside hunters, the hunters will simply find other land.

Again, the land owners are the stronger party in the transaction, and so they are more likely to prefer slowing the release of land usage and negotiation due to a real or perceived mismatch in incentive compatibility [15]. Other things being equal, the land owners and the public, i.e., the hunters in this case, can be modeled as being in states of parallel rationality. They each seek to maximize utility rationally according to their decision strategy. So, utility maximization by one party is reasonably expected to yield a land use level different from that determined by utility maximization by the other party. If that is the case, then they cannot achieve a total market efficient outcome without a bridge.

Bridges can be artificial or natural. Artificial bridges comprise certain types of mechanisms that help to align incentives and improve outcomes, such as an institution established for such a purpose. However, recalling that, in this frame- 
work, decisions are intrinsically probabilistic, there exists a probability, even if the two types (land owners and hunters in this case) are statistically different in expectation, that there will be a choice made by each that will align. Such natural bridges can potentially occur as choices probabilistically align.

\section{Choice Wave Models}

Equation (1) gives a Choice Wave model of the probabilistic decision strategy of land owners, where $k$ is a probability function of some form, $l$ is the principal decision variable, i.e., amount of land willing to open to outside hunters, $x$ is a bundle of all other decisions that might impact choice regarding opening land, $Y$ is the standard income constraint, and $B$ is an artificial bridge, such as an institution designed to bring land owners and hunters together. Interaction between land owners and hunters, as well as interaction between each side and outside parties, may result in influence that impacts decision strategy and hence expectation value of outcome. That is included in Equation (1) as $\frac{F_{n e t}}{n}$ from a multipoint gravitational model [5]. The term $F_{n e t}$ is the net influence of others on the land owner, and $n$ is the strength of the land owner's own influence over others.

$$
\psi(l)_{t}=\left\{\begin{array}{l}
k^{*}(I \mid x) \text { s.t. } v\left(Y, \frac{F_{n e t}}{n}, B\right) \text { at the decision point; } \\
k_{t}(l, x) \text { s.t. } v\left(Y, \frac{F_{n e t}}{n}, B\right) \text { everywhere else. }
\end{array}\right.
$$

In Equation (1), the Choice Wave for land owners is expressed as variable over time except at the decision point, at which time the Choice Wave collapses to a probability of 1 for the selected level of 1 . The expectation value, then, is expressed as some function of the Choice Wave and is given in Equation (2).

$$
\left.\langle l\rangle\right|_{x}=z\left(\psi(l)_{t}\right)
$$

The functional form of $z$ must be such that the expectation value in Equation (2) equals that of the observational revealed preferences. Also, since the Choice Wave in Equation (1) contained the possibility of an artificial bridge, $B$, the expectation value in Equation (2) necessarily changes based on the value of $B$.

The amount of land demanded by hunters may be expressed by a Choice Wave as in Equation (3), which is identical in functional form to that of the land owners, with the addition of the subscript $D$ to indicate different functional forms of the probability and constraint functions for the demand side.

$$
\psi_{D}\left(l_{D}\right)_{t}=\left\{\begin{array}{l}
k_{D}^{*}\left(l_{D} \mid x_{D}\right) \text { s.t. } v_{D}\left(Y, \frac{F_{\text {net }}}{n_{D}}, B\right) \text { at the decision point; } \\
k_{D, t}\left(l_{D}, x_{D}\right) \text { s.t. } v_{D}\left(Y, \frac{F_{\text {net }}}{n_{D}}, B\right) \text { everywhere else. }
\end{array}\right.
$$

In the absence of the bridge, the expectation values for the supply and demand sides are given in Equations (4) and (5) respectively. 


$$
\begin{gathered}
\left.\langle l\rangle\right|_{x, B=0}=z\left(\psi(l)_{t}\right) \\
\left.\left\langle l_{D}\right\rangle\right|_{x, B=0}=z_{D}\left(\psi_{D}\left(l_{D}\right)_{t}\right)
\end{gathered}
$$

Given the orthogonality of the Choice Waves, the expectation values in Equations (4) and (5) clearly cannot be equal. Given that the supply side, i.e., the land owners, are more likely to want to open less land than the hunters want, it is reasonable to assume that $\langle l\rangle\left\langle\left\langle l_{D}\right\rangle\right.$.

If an artificial bridge were to exist, then $B>1$. Assuming it to be a "perfect" bridge that aligns choices absolutely, $z\left(\psi(l)_{t}\right)=z_{D}\left(\psi_{D}\left(l_{D}\right)_{t}\right)$, and so $\left.\langle l\rangle\right|_{x, B=1}=\left.\left\langle l_{D}\right\rangle\right|_{x, B=1}$. Therefore, $z(\psi)=z_{D}\left(\psi_{D}\right)$. Let $M=z_{D}\left(\psi_{D}\left(l_{D}\right)_{t}\right)-z\left(\psi(l)_{t}\right)$, which is excess demand in expectation value. In the presence of a bridge, $M=0$.

Now consider the possibility of a natural bridge. If a natural bridge occurs, and there is no artificial bridge, then $B=0$. Natural bridges are a form of weak interaction that occur when $l \approx l_{D}$ even though $\langle l\rangle \neq\left\langle l_{D}\right\rangle$. That is, the probabilistic outcomes momentarily align. In those cases, the optimal allocation of resources occurs because the utility-maximizing choices of each side align. However, it is only for that specific interaction, as the exact allocation of resources is never known until the decision point. Given its likely rarity, since the expectation values of each side of the transaction are statistically different, the presence of natural bridges is unlikely to eliminate the inefficiencies in the market overall. Indeed, natural bridges could only completely eliminate market inefficiency if they occurred at each and every decision point. Given the different in expectation values, such an occurrence would be expected to have an extremely low probability.

The probability of a natural bridge ought not to be ignored, however. If they occur, they at least create a momentary increase in welfare. If they occur frequently, then the Choice Waves of the two sides, though orthogonal, must be such that they generate expectation values that are statistically different, but not very much so. Also, if a natural bridge occurs, it shows what potential there might be for market improvement and might aid in the development of institutions or mechanisms that could serve as artificial bridges. The probability of a natural bridge occurring is given in Equation (6).

$$
P_{\text {Bridge }}=\sum_{i, j}\left\{\int_{a_{i}}^{a_{j}} \psi(l) \mathrm{d} l+\int_{a_{i}}^{a_{j}} \psi_{D}\left(l_{D}\right) \mathrm{d} l_{D}\right\}
$$

In Equation (6), $a_{i}$ and $a_{j}$ represent all ranges over which there is probabilistic overlap, i.e., the areas where natural alignment of choices may occur. For example there may be low-probability ranges of land use out in the tails of the probability function of both the land owners and the hunters that overlap, even though their expectation values are quite different. The closer the expectation values of the two groups are, the higher $P_{\text {Bridge }}$ is, implying more areas of overlap. With too much overlap, on the other hand, orthogonality disappears, and the 
two groups are merely linear combinations of each others and can be represented by the same Choice Wave. Those regions are areas of weak interaction between the two types, i.e., in this example, the land owners and the hunters. Recall that the Choice Wave permits each choice that may maximize utility and no choice that will not maximize utility. Each utility-maximizing choice has a probability contained within the Choice Wave, and therefore each such choice is possible at the decision point, however likely or unlikely each may be. It is quite theoretically possible that both land owners and hunters may have land use choices that are unlikely for each group, but still could not only occur, but occur simultaneously. That is a natural bridge.

Since an artificial bridge is part of the constraint (see Equation (1)), while it exists, it necessarily causes a temporary shift in the Choice Waves so that incentives and outcomes align. Two worlds of parallel rationality are temporarily linked. A natural bridge, on the other hand, is not part of the constraint because it occurs as a probabilistic alignment of decisions given the existing Choice Waves. Natural bridges may be influenced by other factors in the constraint, such as the behavioural component, which may alter the outcome momentarily for some decision points. Natural bridges can be quickly closed as soon as whatever influenced them to open is removed.

\section{Summary of Land Use Survey Results}

Forty-eight landowners in the NWMN region responded to the land use survey. With a $95 \%$ confidence level, and assuming a total number of land owners of hunting land in all of Minnesota of approximately $4500^{5}$, and a response distribution of $50 \%$, the margin of error is $14.07 \%$. However, it was expected a priori that results would be skewed in the direction of not being willing to open land to outside use. If a response distribution of $88.24 \%$ is assumed, which is the actual distribution in the results, then the margin of error is $9.07 \%$. Neither a margin of error of $9.07 \%$ nor one of $14.07 \%$ is enough to change the interpretation of the results.

Few of the land-owner survey respondents were interested in opening land to outside hunters (or other recreational uses) for a variety of reasons (vide infra). Table 1 provides a summary of respondent answers regarding use of their land for recreational purposes.

As Table 1 indicates, a number of the respondents make quite regular use of their land for themselves across a wide variety of outdoor activities and sports common in the region. There is much less interest in letting outside parties use the land. There is even less interest in opening land to outside parties for profit or pay as opposed to not for profit or pay.

Table 2 gives the acreage dedicated to hunting, though not necessarily

${ }^{5}$ Based on the 2017 list of Deer Landowners in Minnesota provided by the Minnesota Department of Natural Resources. The number of such landowners in northwest Minnesota is clearly much lower. However, assuming a higher number provides a larger margin of error for the calculation, so the margin of error based solely on northwest Minnesota likely is lower. 
Table 1. Frequency of recreational use of land for personal and/or family use.

\begin{tabular}{cccc}
\hline & Primary & Minor & Incidental \\
\hline Own use or family use & 9 & 4 & 2 \\
Outside parties, not for profit or pay & 2 & 2 & 0 \\
Outside parties, for profit or pay & 1 & 1 & 1 \\
\hline
\end{tabular}

Source: Land Use Survey within the EDA Land Use and Recreation Survey Project Report.

Table 2. Acreage dedicated to hunting.

\begin{tabular}{cccccc}
\hline & Min & Max & Std. Dev. & Median & Average \\
\hline Hunting & 0.00 & 1000.00 & 326.58 & 60.00 & 200.56 \\
\hline
\end{tabular}

Source: Land Use Survey within the EDA Land Use and Recreation Survey Project Report.

exclusively. Given the range and standard deviation, there is a wide diversity in terms of amount of land devoted to hunting. Of the respondents to the survey who answered the question, $88.24 \%$ stated that they would not be willing to open their land to outside parties for hunting, while $11.77 \%$ would. Of those who were willing to open their land, however, none indicated a non-zero amount of compensation that they would need to be induced to open land. That is, if it were to be opened, it would be gratis. The following were reasons given for not wanting to open land.

Our family uses this land a lot and we feel allowing others on it would conflict with our use.

We already share this resource with others.

Safety and legal liability issues and concerns.

Do not want people on my land for camping, fishing, snowmobiling, etc. at all.

\section{Land is more valuable for other uses.}

Do not want people on my land for hunting/fishing, etc. that I do not know.

Table 3 provides willingness to pay for hunting (price per day of hunting) by NWMN residents and non-resident US visitors. (Canadian visitors did not indicate a non-zero WTP for hunting.) Both non-resident US visitors and NWMN residents had non-zero WTP values. The value for residents was quite a bit higher than that of non-residents.

\section{Discussion}

The survey results have more contained within them than may be obvious in casual observation. It is clear that the land owners surveyed are far more interested in keeping land for their own recreational purposes. On the other hand, residents indicated what is arguably a non-trivial amount that they are willing to pay for use of land on which to hunt. Non-Resident US visitors likewise are willing to pay, but not to the same degree as residents. That, coupled with a complete lack of willingness on the part of most land owners to open land to 
Table 3. Willingness to pay for Hunting in US\$.

\begin{tabular}{rccc}
\hline & Mean & Std. Dev. & Number \\
\hline NWMN Residents & 88.24 & 237.47 & 17.00 \\
Non-Resident US Visitors & 15.00 & 17.71 & 14 \\
\hline
\end{tabular}

Source: Recreation Survey within the EDA Land Use and Recreation Survey Project Report.

outside hunters supports the anecdotal notion that there are more hunters who desire more land for hunting than there are land owners willing to open their private land. That in turn suggests that the two groups, land owners and hunters, follow separate decision strategies that lead to non-matching group-optimal land use outcomes. Land use is, therefore, sub-optimal.

The results, then, suggest that a pair of Choice Waves of the form indicated in Equation (1) would be logical. Following that, therefore, the values for Equations (4) and (5) are indeed such that $\langle l\rangle\left\langle\left\langle l_{D}\right\rangle\right.$. Given the different decision strategies, incentives of land owners and hunters in the survey clearly do not align, yielding a sub-optimal allocation of land use for hunting.

The Choice Wave and parallel rationality framework can provide additional insight into behaviour of economic actors, supported by mathematical justification. The additional insight can be useful both to understanding a given situation and to policymakers in enacting policy that is appropriately aimed at increasing market efficiency and encouraging optimal outcomes. In the land use case of the present study, such insight is indeed provided, and a path to the alignment of incentives between land owners and hunters in the region becomes clear. Strategic planners and policymakers should focus on re-positioning the concept of opening land to outside use in the minds of land owners. If land owners are currently maximizing utility by not opening their land, such a re-positioning would affect a change to the psychological component of decision strategy in order for opening land to be utility maximizing. One or more bridges are necessary to span the economic worlds of land owners and hunters, which could potentially be in the form of an institution aimed at aligning incentives. In addition, given that many hospitality operations in the region are looking to make arrangements with private land owners for agri-ecotourism, the hospitality industry may be a useful intermediary between the land owner and the guests.

\section{Conclusions}

This study applied a Choice Wave probabilistic model to analyze the potential misalignment in decision strategies regarding land use for hunting between private land owners and hunters in northwest Minnesota. The data were taken from the EDA Northwest Minnesota Recreation and Land Use Survey Project. Even though most land in Minnesota is privately owned, existing anecdotal information suggests that private landowners in northwest Minnesota are on average unwilling to open their land to outside hunters, even for a fee. The present study appears to support that situation as being the case. 
The model employed suggests that the utility-maximizing decision strategy regarding land use is not aligned with that of hunters. This also supports local anecdotal evidence regarding differences between hunters and land owners. This may set up a "tragedy of the anticommons" in which some resources are underused. That, however, creates potential for growth in hunting, particularly commercially. The framework of economic parallel rationality used in the analysis in the present study demonstrates the potential for alignment of incentives through various artificial bridges. Mechanisms to create such outcomes were suggested. Some in the hunting community at large have acknowledged this potential and the need to work for greater involvement of land owners in wildlife management, which includes access to the public. The results of the present study both support that concept and provide additional insight into underlying issues pertaining to decision strategies that can be useful in seeking to bridge gaps, align incentives, improve wildlife management, and increase overall economic efficiency. Both policymakers and private organisations should pursue initiatives that help incentivize private land owners to open their land up to outside hunters.

\section{References}

[1] Watson, R. (2015) Why Private Land? PERC Report, Vol. 34, No. 2.

[2] Heller, M.A. (1998) A Tragedy of the Anti-Commons: Property in the Transition from Marx to Markets. Harvard Law Review, 111, 621-688.

[3] Zheng, L., Pagoulatos, A., Hu, W. and Ronald Fleming, A. (2010) The Supply of Private Acreage for Public Recreational Use in Southern and Central Appalachia. Growth and Change, 41, 540-555. https://doi.org/10.1111/j.1468-2257.2010.00538.x

[4] Chang, Y.-C. and Smith, H.E. (2012) An Economic Analysis of Common vs. Civil Law Property. Notre Dame Law Review, 88, 1-55.

[5] Johnson, R.C. (2017) An Economic Multipoint Gravitational Model Expression of a Transactional Analysis Game: An Application to Recreational Private Land Use Decisions. Journal of Applied Business Research, 33, 791-800. https://doi.org/10.19030/jabr.v33i4.10000

[6] D'Amato, D., Rekola, M., Wan, M., Cai, D. and Toppinen, A. (2017) Effects of Industrial Plantations on Ecosystem Services and Livelihoods: Perspectives of Rural Communities in China. Land Use Policy, 23, 266-278. https://doi.org/10.1016/j.landusepol.2017.01.044

[7] Bennett, E.M., Cramer, W., Begossi, A., Cundill, G., Díaz, S., Egoh, B.N., Geizendorffer, I.R., Krug, C.B., Lavorel, S., Lazos, E., Lebel, L., Martín-López, B., Meyfroidt, P., Mooney, H.A., Nel, J.L., Pascual, U., Payet, K., Harguindeguy, N.P., Peterson, G.D. Prieur-Richard, A.-H., Reyers, B., Roebeling, P., Seppelt, R., Solan, M., Tschaker, P., Tscharnetke, T., Turner II, B.L. and Verburg, P.H. (2015) Linking Biodiversity, Ecosystem Services, and Human Well-Being: Three Challenges for Designing Research for Sustainability. Current Opinion in Environmental Sustainability, 14, 76-85. https://doi.org/10.1016/j.cosust.2015.03.007

[8] Demsetz, H. (1967) Toward a Theory of Property Rights. American Economic Review, 57, 347-359.

[9] Constantin, C., Luminita, C. and Vasile, A.J. (2017) Land Grabbing: A Review of 
Extent and Possible Consequences in Romania. Land Use Policy, 62, 143-150. https://doi.org/10.1016/j.landusepol.2017.01.001

[10] Vereshchagina, G. and Hopenhayn, H.A. (2009) Risk Taking by Entrepreneurs. American Economic Review, 99, 1808-1830. https://doi.org/10.1257/aer.99.5.1808

[11] Johnson, R.C. and Walker, E. (2017) EDA Land Use and Recreation Survey Project Report. Report Given to the Economic Development Administration and the University of Minnesota.

[12] Johnson, R.C. (2012) The Choice Wave: An Alternative Description of Consumer Behavior. Research in Business and Economics Journal, 5, 1-16.

[13] Johnson, R.C. (2016) A Probabilistic Demand Application in the American Cracker Market. International Journal of Food and Agricultural Economics, 4, 49-61.

[14] Chang, H.-H. (2017) Does a Social Welfare Program Affect Farmland Use? Empirical Evidence using Administrative Data in Taiwan. Applied Economic Perspectives and Policy, 39, 441-457. https://doi.org/10.1093/aepp/ppx024

[15] Garicano, L. and Rayo, L. (2017) Relational Knowledge Transfers. American Economic Review, 107, 2695-2730. https://doi.org/10.1257/aer.20160194 


\section{Appendix}

The following is the original transcript of the three surveys from which the data were gathered. The transcript was then programmed into the Qualtrics system with appropriate modifications for the system and administered via the internet.

\section{Northwest Minnesota Land Use Survey}

Administered to Land Owners in the Northwest Minnesota area.

Category 1: Demographics

The order of presentation of each sub-category should be randomly varied among survey respondents.

LOCATION:ZIP Code, State, County

AGE: 18-22, 23-27, 28-32, 33-37, 38-42, 43-47, 48-52, 53-57, 58-62, 63-67, 68-72, 73-77, Over 77

OCCUPATION: Free response question - state occupation.

INCOME: "Please indicate the range in which your pre-tax average annual income falls."

$\$ 0$ - $\$ 15,000 ; \$ 15,001-\$ 20,000 ; \$ 20,001-\$ 30,000 ; \$ 30,001-\$ 40,000 ; \$ 40,001$ $\$ 55,000 ; \$ 55,001-\$ 70,000$;

$\$ 70,001$ - \$100,000; $\$ 100,000$ - \$150,000; Over $\$ 150,000$

ETHNIC BACKGROUND: "Please choose one or more of the following."

White, not Hispanic, Hispanic, Latino, African/Black, Native American/ American Indian, Alaskan Native,

Asian, Pacific Islander, Other (Please state):

EDUCATION: None, Elementary School, Middle School, Some High School, High School Graduate, Some College, 2-year College Degree (Associate's Degree or equivalent), Vocation Training (non-degree, such as professional certification), 4-year College Degree (Bachelor's Degree or equivalent), Some graduate school, Master's Degree (or equivalent), Specialist Degree, Doctorate “ABD” (All-But-Dissertation), Doctoral Degree (Professional, e.g., MD, DMD, JD, DPharm), Doctoral Degree (Academic, e.g., $\mathrm{PhD}, \mathrm{DSc}$ ), More than one doctoral degree.

MARITAL STATUS: Single, never married; Married; Divorced; Widow/Widower; Other;

SEX: Male; Female

\section{Category 2: Current Land Use}

The order of presentation of the following land use choices within each subcategory AND the order of presentation of the subcategories should be randomly varied among survey respondents.

There should be three mutually-exclusive selection buttons next to each choice as follows:

[] Primary Use [] Minor Use [] Incidental Use

"Please indicate which of the following uses of your land apply. You may choose as many as apply. If the item is a primary use for you, please check the 'Primary Use' button next to the choice. If it is a minor use for your land, please 
check the 'Minor Use' button. If it is incidental, then please check the 'Incidental Use' button.”

TIMBER \& SHRUBBERY: Timber Growth (for commerce); Timber Growth (environmental); Trees (for sale, for planting); Shrubbery and Plants for Sale for Gardening; Shrubbery and Plants for Gardening (personal use)

CASH CROPS: Sugar Beets; Sunflowers; Corn (for consumption); Corn (for biofuels); Corn (non-GM); Corn (GM); Soybeans; Hay; Potatoes; Beans (for consumption); Oats; Barley; Wheat; Other:

LIVESTOCK: Cattle; Buffalo; Horses; Sheep; Swine; Others:

REAL ESTATE: Inherited Land; Sell land for Profit (If yes, then how much total revenue expected?); Rent land (If yes, then how much total revenue?); Tax shelter; Second home; Leave land to heirs; Other:

PERSONAL \& FAMILY RECREATIONAL USES: Hunting; Fishing (except ice fishing); Ice Fishing; Camping; Horseback riding; Four-wheeling and other off-road vehicles; Golf; Hiking; Skiing; Snowmobiling; Snowshoeing; Other:

RECREATIONAL USES (NOT FOR PROFIT/PAY): Hunting; Fishing (except ice fishing); Ice Fishing; Camping; Horseback riding; Four-wheeling and other off-road vehicles; Golf; Hiking; Skiing; Snowmobiling; Snowshoeing; Other:

RECREATIONAL USES BY OTHERS (FOR PROFIT/PAY): Hunting; Fishing (except ice fishing); Ice Fishing; Camping; Horseback riding; Four-wheeling and other off-road vehicles; Golf; Hiking; Skiing; Snowmobiling; Snowshoeing; Other:

MINING: List Minerals Mined:

ENVIRONMENTAL USE: Preserve greenspace; Land reclamation; Preserve wildlife; Other:

AGRITOURISM \& ECOTOURISM: Agritourism; Ecotourism; Other:

\section{Category 3: Potential Land Use by Outside Persons}

The order of presentation of the following questions should be randomly varied among survey respondents.

Q1. Are you willing to open your land up to outside persons you do not know personally for consumptive uses, such as hunting and fishing, either for free or for a usage fee? YES/NO

If "Yes: "'Please indicate which of the following activities you would consider permitting on your land for people you do not know personally: "

[] Hunting; [] Fishing (except ice fishing); [] Ice Fishing; [] Other:

If "No: "

Q1-1. Why not? (select all that apply)

a. Do not want people I don't know on my land for hunting/fishing, etc.

b. Land is more valuable for other uses.

c. Security issues and concerns. 
d. Safety and legal liability issues and concerns.

e. Other:

Q2. Are you willing to open your land up to outside persons you DO know personally other than family members for consumptive uses, such as hunting and fishing, either for free or for a usage fee? YES/NO

If "Yes: "'Please indicate which of the following activities you would consider permitting on your land for people you do know personally: "

[] Hunting; [] Fishing (except ice fishing); [] Ice Fishing; [] Other:

\section{If "No:"}

Q1-1. Why not? (select all that apply)

a. Do not want people on my land for hunting/fishing, etc., even if I know them.

b. Land is more valuable for other uses.

c. Security issues and concerns.

d. Safety and legal liability issues and concerns.

e. Other:

Q3. Are you willing to open your land up to outside persons you do not know personally for non-consumptive uses, such as hiking, camping, snowmobiling, etc., either for free or for a usage fee? YES/NO

If "Yes: "'Please indicate which of the following activities you would consider permitting on your land for people you do not know personally: "

[] Camping; [] Horseback riding; [] Four-wheeling and other off-road vehicles; [] Golf; [] Hiking; [] Skiing; [] Snowmobiling;

[] Snowshoeing; [] Other:

If "No:"

Q1-1. Why not? (select all that apply)

a. Do not want people I don't know on my land for camping, fishing, snowmobiling, etc. at all.

b. Land is more valuable for other uses.

c. Security issues and concerns.

d. Safety and legal liability issues and concerns.

e. Other:

Q4. Are you willing to open your land up to outside persons you DO know personally other than family members for non-consumptive uses, such as hiking, camping, snowmobiling, etc., either for free or for a usage fee? YES/NO

If "Yes: "'Please indicate which of the following activities you would consider permitting on your land for people you do not know personally: "

[] Camping; [] Horseback riding; [] Four-wheeling and other off-road vehicles; [] Golf; [] Hiking; [] Skiing; [] Snowmobiling;

[] Snowshoeing; [] Other:

If "No:"

Q1-1. Why not? (select all that apply) 
a. Do not want people on my land for camping, fishing, snowmobiling, etc. at all, even if I know them.

b. Land is more valuable for other uses.

c. Security issues and concerns.

d. Safety and legal liability issues and concerns.

e. Other:

Q5. Are you willing to establish a partnership with hotels and/or other similar facilities and open your land up to outside persons through that partnership for agritourism and/or ecotourism purposes?

YES/NO/I AM ALREADY INVOLVED IN AGRITOURISM PARTNERSHIPS

If "Yes: "Please indicate which of the following activities you would consider permitting on your land for agritourism/ecotourism through partnerships with hotels and other similar facilities: "

[] Camping; [] Horseback riding; [] Four-wheeling and other off-road vehicles; [] Golf; [] Hiking; [] Skiing; [] Snowmobiling;

[] Snowshoeing; [] Other:

If "No: "

Q1-1. Why not? (select all that apply)

a. Do not want people on my land for camping, fishing, snowmobiling, etc.

b. Land is more valuable for other uses.

c. Security issues and concerns.

d. Safety and legal liability issues and concerns.

e. I am not interested in partnerships with hotels.

f. I have tried partnerships with hotels in the past, and they were unsuccessful. [If (f), then: Please explain:

g. Other:

Q6-10. Repeat Q1-5 phrased as "Currently is your land available for...”

"If so, how many acres for..."

Q11-15. Repeat Q1-5 phrased as "In the past, have you opened up your land for..."

"If so, how many acres for..."

\section{Category 4: Land Use Valuation and Quantification}

Note that this section is omitted if the respondent in Category 3 indicated "No" to all questions, i.e., is not interested in opening land to outside use in any circumstance whatsoever.

The Questions display in the order provided.

Pre-Survey Version:

Q1: "For use of your land by outside persons, how much would you charge perperson for a single use for: "

[Display list of all land use options the respondent selected in Category 3]

Q2: "How many acres of your land would you be willing to open up for use by outside persons (other than agritourism/ecotourism) for: "

[Display list of all land use options the respondent selected in Category 3] 
Q3: "How many acres of your land would you be willing to open up specifically for agritourism/ecotourism for: "

[Display list of all land use options the respondent selected in Category3]

Final Version:

(Subject to results of the pre-survey and any necessary modifications determined therefrom.)

Q1: "For each of the following land use choices, please indicate whether or not you would accept $\$ \mathrm{X}$ per person for a single use." (\$X is determined from the results of the pre-survey. There may be more than one value of $\$ \mathrm{X}$, and if so, the bid shown for a given respondent will be chosen by the computer randomly from the set of options."

[Display list of all land use options the respondent selected in Category 3. Next to each is a pair of mutually-exclusive radio buttons, one named "Accept," the other "Decline."]

Q2: "For each of the following land use choices for which you accepted the offer, is there a lower amount you would be willing to accept? If so, please type it in the blank space next to the specific land use."

[Display list of all land use options for which the respondent accepted the offer in Q1. Next to each is an entry box into which an amount may be typed.]

Q3: "For each of the following land use choices for which you did not accept the offer, what is the amount that you would be willing to accept? If so, please type it in the blank space next to the specific land use."

[Display list of all land use options for which the respondent did not accept the offer in Q1. Next to each is an entry box into which an amount may be typed.]

Q4: “How many acres of your land would you be willing to open up for use by outside persons (other than agritourism/ecotourism) in exchange for the monetary compensation you selected for: "

[Display list of all land use options the respondent selected in Category 3]

Q5: "How many acres of your land would you be willing to open up specifically for agritourism/ecotourism in exchange for the monetary compensation you selected for: "

[Display list of all land use options the respondent selected in Category 3]

\section{Northwest Minnesota Recreation Amenities Survey}

Administered to Residents in and Former/Current/Potential

Visitors to the Northwest Minnesota area.

\section{Category 1: Demographics}

The order of presentation of each sub-category should be randomly varied among survey respondents.

LOCATION:

ZIP Code

State

County 
LOCATION: ZIP Code, State, County

AGE: 18-22, 23-27, 28-32, 33-37, 38-42, 43-47, 48-52, 53-57, 58-62, 63-67, 68-72, 73-77, Over 77

OCCUPATION: Free response question - state occupation.

INCOME: "Please indicate the range in which your pre-tax average annual income falls."

$\$ 0$ - \$15,000; $\$ 15,001$ - \$20,000; $\$ 20,001$ - \$30,000; $\$ 30,001$ - \$40,000; $\$ 40,001$ $\$ 55,000 ; \$ 55,001$ - \$70,000; $\$ 70,001$ - \$100,000; $\$ 100,000$ - \$150,000; Over $\$ 150,000$

ETHNIC BACKGROUND: "Please choose one or more of the following."

White, not Hispanic, Hispanic, Latino, African/Black, Native American/ American Indian, Alaskan Native,

Asian, Pacific Islander, Other (Please state):

EDUCATION: None, Elementary School, Middle School, Some High School, High School Graduate, Some College, 2-year College Degree (Associate's Degree or equivalent), Vocation Training (non-degree, such as professional certification), 4-year College Degree (Bachelor's Degree or equivalent), Some graduate school, Master's Degree (or equivalent), Specialist Degree, Doctorate “ABD” (All-But-Dissertation), Doctoral Degree (Professional, e.g., MD, DMD, JD, DPharm), Doctoral Degree (Academic, e.g., $\mathrm{PhD}, \mathrm{DSc}$ ), More than one doctoral degree.

MARITAL STATUS: Single, never married; Married; Divorced; Widow/Widower; Other;

SEX: Male; Female

HOUSEHOLD SIZE: "How many people live in your household (including you)?" (Include mutually-exclusive selection buttons for 1-10 and then "over 10.")

HOUSEHOLD AGE: For those who indicated household size of more than 1: "Please give the age range of any children living in your household."(Provide a free-response space and a radio button that says "There are no children living in my household.")

Category 2: Past Use of NW Minnesota Recreational Facilities by Non-

\section{Residents}

This category is only for those whose ZIP codes place them outside NW Minnesota.

The following questions are presented in the order given.

1. Have you or any of your immediate family living in your household travelled to northwest Minnesota?"Select all that apply."

[] I have travelled to NW Minnesota; [] My spouse; [] My children; [] No one has travelled to Northwest Minnesota.

(Note: The last option is mutually exclusive to the other three.)

(If the answer to \#1 was any of the first three choices, then the following questions are asked. Otherwise, the survey skips to Category4.) 
2. What was the purpose of your visit? "Check all that apply."

[] Business; [] Short vacation/trip (no more than a long weekend); [] Long vacation/trip (a week or more); [] Extended vacation/trip (four or more weeks); [] Visiting family in the area

3. When you visited, did/do you stay primarily with commercial hospitality or with family? (Not displayed unless “Visiting family” was selected in \#2.)

Check one: [] Commercial Hospitality (Hotels/Motels/Campgrounds, etc.); [] Family

4. Which of the following accommodations have you ever used in northwest Minnesota? "Check all that apply."

[] Hotels/Motels; [] Native American Resorts; [] Other Resorts; [] Primitive camping; [] RV campgrounds; [] Rustic cabins; [] Other ; [] None

5. Of the accommodations you selected, which is your most frequently used? "Check only one."

[] Hotels/Motels; [] Native American Resorts; [] Other Resorts; [] Primitive camping; [] RV campgrounds; [] Rustic cabins; [] Other ; [] None

6. What activities did you participate in while in Northwest Minnesota? "Select all that apply."

[] Fishing (on your own); [] Fishing (with professional guide); [] Ice Fishing; [] Boating; [] Hiking; [] Camping; [] Commercially-operated tours; [] Cross-country skiing; [] Downhill Skiing; [] Biking; [] Golf; [] Kayaking; [] Canoeing; [] Swimming in lakes/rivers; [] Horseback riding; [] Local festivals (Which one(s)___ ); [] Local events (Which one(s) ___ ); [] Arts and Culture (Please specify: ___ _ ); [] Indian Gaming; [] Adventure Parks and Amusement Parks; [] Native American Events; [] Sporting Events (Which one(s): ____); [] Bird Watching; [] Hunting; [] ATV Riding; [] Snowmobiling; [] Other

6A. (Follow-up question: Displays only if hunting is chosen.)

"When hunting, what type of land do you primarily use in Northwest Minnesota?" Check all that apply.

[] Land I own myself; [] Family-owned land; [] Land owned by a friend (used without payment); [] Land owned by a friend (used with payment); [] Land opened by landowner for a fee; [] Public land (used without payment); [] Public land (used with payment); [] Native American Reservation Land (used by personal tribal right); [] Native American Reservation Land (used withoutpayment); [] Native American Reservation Land (used with payment); [] Other:

6B. (Follow-up question: Displays only if fishing is chosen.)

"When fishing, what type of land do you primarily use in Northwest Minnesota?" Check all that apply.

Same options as given in Question $6 \mathrm{~A}$.

6C. (Follow-up question: Displays only if ice fishing is chosen.)

"When ice fishing, what type of land do you primarily use in Northwest Minnesota?" Check all that apply.

Same options as given in Question $6 \mathrm{~A}$. 
6D. (Follow-up question: Displays only if hiking or camping are chosen.)

"When hiking or camping, what type of land do you primarily use in Northwest Minnesota?"Check all that apply.

Same options as given in Question $6 \mathrm{~A}$.

6E. (Follow-up question: Displays only if ATV riding or snowmobiling are chosen.)

"When riding ATVs or snowmobiles, what type of land do you primarily use in Northwest Minnesota?"Check all that apply.

Same options as given in Question 6 A.

6F. (Follow-up question: Displays only if Bird watching is chosen.)

"When bird watching, what type of land do you primarily use in Northwest Minnesota?"Check all that apply.

Same options as given in Question 6 A.

6G. (Follow-up question: Displays only if horseback riding is chosen.)

"When horseback riding, what type of land do you primarily use in Northwest Minnesota?" Check all that apply.

Same options as given in Question $6 \mathrm{~A}$.

6G. (Follow-up question: Displays only if Canoeing, Kayaking, or Boating are chosen.)

"When boating in Northwest Minnesota, where is the water access primarily located?" Check all that apply.

Same options as given in Question $6 \mathrm{~A}$.

7. What time of year do you or have you ever come to Northwest Minnesota? "Select all that apply."

[] Summer; [] Early Fall; [] Late Fall; [] Winter; [] Early Spring; [] Late Spring

8. What is the most frequent time you come or have ever come to Northwest Minnesota? "Select only one."

Note: The following are mutually-exclusive radio buttons.

[] Summer; [] Early Fall; [] Late Fall; [] Winter; [] Early Spring; [] Late Spring

9. How did/do you travel to Northwest Minnesota? "Select all that apply."

[] Commercial airline; [] Private/charter airline; [] Personal vehicle; [] Company vehicle (for business travel only); [] Commercially-operated vehicle (such as a bus); [] Group vehicle (such as a church or school bus); [] Other

10. Of the means of travel you use or have used to come to Northwest Minnesota, what is the one you use the most frequently? "Select only one."

Note: These should be mutually-exclusive radio buttons.

[] Commercial airline; [] Private/charter airline; [] Personal vehicle; [] Company vehicle (for business travel only); [] Commercially-operated vehicle (such as a bus); [] Group vehicle (such as a church or school bus); [] Other

11. If you drive or have driven a vehicle, or ride or have ridden in a vehicle when travelling to Northwest Minnesota, what type(s) of vehicle(s) were they? "Select all that apply."

[] Passenger automobile; [] Passenger van; [] Large passenger van (15-passen- 
ger); [] Bus (I was the driver); [] Bus (I was a passenger); [] Church van/bus; [] School van/bus; [] Motorcycle (Indicate type: ); [] RV (self-contained); [] RV (trailer, towed by vehicle); [] Other

12. When in Northwest Minnesota, what type of dining options do you or have you ever chosen? "Select all that apply."

[] Local (not chain) restaurants; [] Local restaurants featuring locally-sourced food; [] Farm-to-table restaurants; [] Fast food; [] Self-prepared (such as cooking at a campsite); [] Fine dining; [] Casual dining; [] Other

13. Which is/was your most common dining choice when you are in or were in Northwest Minnesota? "Select only one."

[] Local (not chain) restaurants; [] Local restaurants featuring locally-sourced food; [] Farm-to-table restaurants; [] Fast food; [] Self-prepared (such as cooking at a campsite); [] Fine dining; [] Casual dining; [] Other

14. If you stayed at a hotel or other commercial hospitality accommodation in Northwest Minnesota, did that facility where you stayed provide you with any information on local agritourism or ecotourism options?

[] Yes, agritourism only; [] Yes, ecotourism only; [] Yes, both agritourism and ecotourism; [] No, they did not provide information.

15. If you stayed at a hotel or other commercial hospitality accommodation in Northwest Minnesota, did that facility where you stayed organize specific opportunities for local agritourism or ecotourism?

[] Yes, agritourism only; [] Yes, ecotourism only; [] Yes, both agritourism and ecotourism; [] No, they did not provide information.

Category 3: Past Use of NW Minnesota Recreational Facilities by Residents

This category is ONLY for those whose ZIP codes place them INSIDE NW Minnesota.

The following questions are presented in the order given.

1. How long have you lived in Northwest Minnesota? Years: Months:

2. Why do you live in Northwest Minnesota? "Select all that apply."

[] Native (Born in NW Minnesota, lived only there); [] Native (Born in NW Minnesota, moved away, returned); [] Came for work; [] Family member came for work and I moved as well; [] Family moved here as a child; [] Recreational opportunities; [] Proximity to family; [] Other:

3. Do you take vacations in Northwest Minnesota? YES/NO

IF "Yes," THEN "What types of vacations do you take in the area?" "Check all that apply."

[] Short vacation/trip (no more than a long weekend); [] Long vacation/trip (a week or more); [] Extended vacation/trip (four or more weeks); [] Visiting family in the area; [] Other

Questions \#4, \#5, and \#6 only display if the answer to \#3 was YES. Else skip to $\#$. 
4. When you vacation in Northwest Minnesota, did/do you stay primarily with commercial hospitality or with family?

(Not displayed unless “Visiting family" was selected in \#3.) “Check one."

[] Commercial Hospitality (Hotels/Motels/Campgrounds, etc.); [] Family

5. Which of the following accommodations have you ever used in northwest Minnesota when on vacation? "Check all that apply."

[] Hotels/Motels; [] Native American Resorts; [] Other Resorts; [] Primitive camping; [] RV campgrounds; [] Rustic cabins; [] Other ; [] None

6. Of the accommodations you selected, which is your most frequently used? "Check only one."

[] Hotels/Motels; [] Native American Resorts; [] Other Resorts; [] Primitive camping; [] RV campgrounds; [] Rustic cabins; [] Other ; [] None

7. What recreational activities do you participate in or have you ever participated in within Northwest Minnesota? "Select all that apply."

[] Fishing (on your own); [] Fishing (with professional guide); [] Ice Fishing; [] Boating; [] Hiking; [] Camping; [] Commercially-operated tours; [] Cross-country skiing; [] Downhill Skiing; [] Biking; [] Golf; [] Kayaking; [] Canoeing; [] Swimming in lakes/rivers; [] Horseback riding; [] Local festivals (Which one(s)___ ); [] Local events (Which one(s)___ ); [] Arts and Culture (Please specify: ___ ); [] Indian Gaming; [] Adventure Parks and Amusement Parks; [] Native American Events; [] Sporting Events (Which one(s): ___); [] Bird Watching; [] Hunting; [] ATV Riding; [] Snowmobiling; [] Other ___; [] None

7A. (Follow-up question: Displays only if hunting is chosen.)

"When hunting, what type of land do you primarily use in Northwest Minnesota?" Check all that apply.

[] Land I own myself; [] Family-owned land; [] Land owned by a friend (used without payment); [] Land owned by a friend (used with payment); [] Land opened by landowner for a fee; [] Public land (used without payment); [] Public land (used with payment); [] Native American Reservation Land (used by personal tribal right); [] Native American Reservation Land (used without payment); [] Native American Reservation Land (used with payment); [] Other:

7B. (Follow-up question: Displays only if fishing is chosen.)

"When fishing, what type of land do you primarily use in Northwest Minnesota?" Check all that apply.

Same options as in Question 7A, plus: [] Land arranged by a private/commercial fishing guide.

7C. (Follow-up question: Displays only if ice fishing is chosen.)

"When ice fishing, what type of land do you primarily use in Northwest Minnesota?" Check all that apply.

Same options as in Question $7 B$.

7D. (Follow-up question: Displays only if hiking or camping are chosen.) 
"When hiking or camping, what type of land do you primarily use in Northwest Minnesota?"Check all that apply.

Same options as in Question 7 A.

7E. (Follow-up question: Displays only if ATV riding or snowmobiling are chosen.)

"When riding ATVs or snowmobiles, what type of land do you primarily use in Northwest Minnesota?"Check all that apply.

Same options as in Question $7 \mathrm{~A}$.

7F. (Follow-up question: Displays only if Bird watching is chosen.)

"When bird watching, what type of land do you primarily use in Northwest Minnesota?"Check all that apply.

Same options as in Question 7 A.

7G. (Follow-up question: Displays only if horseback riding is chosen.)

"When horseback riding, what type of land do you primarily use in Northwest Minnesota?"Check all that apply.

Same options as in Question 7 A, plus: [] Commercial riding facility.

7G. (Follow-up question: Displays only if Canoeing, Kayaking, or Boating are chosen.)

"When boating in Northwest Minnesota, where is the water access primarily located?"Check all that apply.

Same options as in Question 7A, plus: [] Commercially-operated boating service facility.

8. What time of year do you participate in recreational activities within Northwest Minnesota? "Select all that apply."

[] Summer; [] Early Fall; [] Late Fall; [] Winter; [] Early Spring; [] Late Spring; [] None

9. What is the most frequent time you participate in recreational activities within Northwest Minnesota? "Select only one."

[] Summer; [] Early Fall; [] Late Fall; [] Winter; [] Early Spring; [] Late Spring; [] None

10. What type(s) of vehicle do you own and/or drive within Northwest Minnesota? "Select all that apply."

[] Passenger automobile; [] Passenger van; [] Large passenger van (15-passenger); [] Bus (I was the driver); [] Bus (I was a passenger); [] Church van/bus; [] School van/bus; [] Motorcycle (Indicate type: ); [] RV (self-contained);

[] RV (trailer, towed by vehicle); [] Other ; [] None

11. In Northwest Minnesota, what type of dining options do you or have you ever chosen? "Select all that apply."

[] Local (not chain) restaurants; [] Local restaurants featuring locally-sourced food; [] Farm-to-table restaurants; [] Fast food; [] Camp cooking; [] Fine dining; [] Casual dining; [] Other ; [] I do not go to commercial dining/restaurants.

12. Which is/was your most common dining choice when you are in or were in Northwest Minnesota? "Select only one." 
NOTE: Does not display if answer to \#11 was "I do not go to commercial dining/restaurants."

[] Local (not chain) restaurants; [] Local restaurants featuring locally-sourced food; [] Farm-to-table restaurants; [] Fast food; [] Camp cooking; [] Fine dining; [] Casual dining; [] Other __; [] I do not go to commercial dining/restaurants.

Category 4: Willingness to Pay for NW Minnesota Recreational Facilities by Non-Residents

This category is only for those whose ZIP codes place them outside NW Minnesota.

The following questions are presented in the order given. The open-ended (free response) bids received in the pre-survey will be used to establish one or more starting-point bids for the final survey.

1. How much are you willing to pay per day for each the following?

(Note: Only those items that the respondent identified as being of interest in Category 2 will display. If the respondent selected none, then this question is skipped.)

[] Fishing (on your own); [] Fishing (with professional guide); [] Ice Fishing; [] Boating; [] Hiking; [] Camping; [] Commercially-operated tours; [] Cross-country skiing; [] Downhill Skiing; [] Biking; [] Golf; [] Kayaking; [] Canoeing; [] Swimming in lakes/rivers; [] Horseback riding; [] Local festivals (Which one(s)___); [] Local events (Which one(s) ___); [] Arts and Culture (Please specify: ___ ); [] Indian Gaming; [] Adventure Parks and Amusement Parks; [] Native American Events; [] Sporting Events (Which one(s): ____); [] Bird Watching; [] Hunting; [] ATV Riding; [] Snowmobiling; [] Other

2. When in Northwest Minnesota, how much are you willing to pay per meal per person (excluding tax) for the following dining options?

[] Local (not chain) restaurants; [] Local restaurants featuring locally-sourced food; [] Farm-to-table restaurants; [] Fast food; [] Camp cooking; [] Fine dining; [] Casual dining; [] Other __; [] I do not go to commercial dining/restaurants.

3. Would you be more likely to participate in agritourism and ecotourism if the hotel or facility where you were staying in Northwest Minnesota offered an agritourism and/or ecotourism package, promotion, or discount in cooperation with local service providers? YES/NO.

Category 5: Willingness to Pay for NW Minnesota Recreational Facilities by Residents

This category is only for those whose ZIP codes place them inside NW Minnesota.

The following questions are presented in the order given. The open-ended (free response) bids received in the pre-survey will be used to establish one or more starting-point bids for the final survey.

1. How much are you willing to pay per day for each the following?

(Note: Only those items that the respondent identified as being of interest in Category 3 will display. If the respondent selected none, then this question is 
skipped.)

[] Fishing (on your own); [] Fishing (with professional guide); [] Ice Fishing; [] Boating; [] Hiking; [] Camping; [] Commercially-operated tours; [] Cross-country skiing; [] Downhill Skiing; [] Biking; [] Golf; [] Kayaking; [] Canoeing; [] Swimming in lakes/rivers; [] Horseback riding; [] Local festivals (Which one(s) ); [] Local events (Which one(s) ); [] Arts and Culture (Please specify: ); [] Indian Gaming; [] Adventure Parks and Amusement Parks; [] Native American Events; [] Sporting Events (Which one(s): ); [] Bird Watching; [] Hunting; [] ATV Riding; [] Snowmobiling; [] Other

2. When in Northwest Minnesota, how much are you willing to pay per meal per person (excluding tax) for the following dining options?

[] Local (not chain) restaurants; [] Local restaurants featuring locally-sourced food; [] Farm-to-table restaurants; [] Fast food; [] Camp cooking; [] Fine dining; [] Casual dining; [] Other __; [] I do not go to commercial dining/restaurants.

3. Would you be more likely to participate in agritourism and ecotourism if the hotel or facility where you were staying on a trip in Northwest Minnesota offered an agritourism and/or ecotourism package, promotion, or discount in cooperation with local service providers? YES/NO

4. How far are you willing to travel in hours of travel time for a day trip for each the following activities?

(Note: Only those items that the respondent identified as being of interest in Category 3 will display. If the respondent selected none, then this question is skipped.)

[] Fishing (on your own); [] Fishing (with professional guide); [] Ice Fishing; [] Boating; [] Hiking; [] Camping; [] Commercially-operated tours; [] Cross-country skiing; [] Downhill Skiing; [] Biking; [] Golf; [] Kayaking; [] Canoeing; [] Swimming in lakes/rivers; [] Horseback riding; [] Local festivals (Which one(s)___ ); [] Local events (Which one(s) ___ ); [] Arts and Culture (Please specify: ___ ); [] Indian Gaming; [] Adventure Parks and Amusement Parks; [] Native American Events; [] Sporting Events (Which one(s): ___); [] Bird Watching; [] Hunting; [] ATV Riding; [] Snowmobiling; [] Other

5. How far are you willing to travel in hours of travel time for an overnight trip or longer for each the following activities?

(Note: Only those items that the respondent identified as being of interest in Category 3 will display. If the respondent selected none, then this question is skipped.)

[] Fishing (on your own); [] Fishing (with professional guide); [] Ice Fishing; [] Boating; [] Hiking; [] Camping; [] Commercially-operated tours; [] Cross-country skiing; [] Downhill Skiing; [] Biking; [] Golf; [] Kayaking; [] Canoeing; [] Swimming in lakes/rivers; [] Horseback riding; [] Local festivals (Which one(s) ); [] Local events (Which one(s) ); [] Arts and Culture (Please specify: ); [] Indian Gaming; [] Adventure Parks and Amusement Parks; [] Native American Events; [] Sporting Events (Which one(s): ); [] 
Bird Watching; [] Hunting; [] ATV Riding; [] Snowmobiling; [] Other

Northwest Minnesota Agritourism \& Ecotourism Survey for Hoteliers and Hospitality Service Providers

Administered to Hotels, Motels, Campgrounds, and other Hospitality Service Providers

in the Northwest Minnesota area.

Category 1: Demographics of Guests

1. Please provide the approximate percentage of your total annual guests from: [] The United States; [] Canada; [] Other Foreign Countries (please indicate which ones)

2. Please provide the approximate percentage of your total annual guests from: [] Northwest Minnesota; [] Red River Valley other than Northwest Minnesota); [] Other Locations in Minnesota, North Dakota, South Dakota, and Wisconsin; [] Other States (please indicate the top states from which your guests come)

3. Please indicate the most common age-range of your guests: [] 18-24; [] 25-29; [] 30-35; [] 36-45; [] 46-55; [] 56-65; [] Over 65

4. Approximately what percentage of your guests are travelling on business?

5. Approximately what percentage of your guests are accompanied by teenage children?

6. Approximately what percentage of your guests are accompanied by small children?

7. Approximately how many guests do you have in a year?

8 . What is your average nightly rate in the summer?

$\ldots$ in the winter?

$\ldots$ in the fall?

... in the spring?

9. How long on average to guests typically stay at your facility?

Category 2: Current Agritourism and Ecotourism Advertising \& Arrangements

The following questions are presented in the order given.

1. Do you advertise local agritourism and/or ecotourism? "Select all that apply."

[] Brochures (such as in a lobby display); [] Information provided in-room; [] Other types of flyers; [] Email promotions and information sent to guests prior to arrival; [] Email promotions and information sent to guests after departure; [] Ads placed on in-house television system; [] Front desk agent directly informs guest as part of check-in procedure; [] Signage within building; [] On existing hotel internet advertisement; [] On hotel website; [] Other (please indicate)

2. Do you have promotional or other arrangements with local commercial service providers in any of the following activities? "Select all that apply."

[] Fishing; [] Ice Fishing; [] Boating; [] Hiking; [] Camping; [] Commercially-operated tours; [] Cross-country skiing; [] Downhill Skiing; [] Biking; [] Golf; 
[] Kayaking; [] Canoeing; [] Swimming in lakes/rivers; [] Horseback riding; [] Local festivals (Which one(s)___ ); [] Local events (Which one(s) ___); [] Arts and Culture (Please specify: __ ); [] Indian Gaming; [] Adventure Parks and Amusement Parks; [] Native American Events; [] Sporting Events (Which one(s): ___ ); [] Bird Watching; [] Hunting; [] ATV Riding; [] Snowmobiling; [] Other

3. Do you have promotional or other arrangements with local private land owners for any of the following activities? "Select all that apply."

[] Fishing; [] Ice Fishing; [] Boating; [] Hiking; [] Camping; [] Commercially-operated tours; [] Cross-country skiing; [] Downhill Skiing; [] Biking; [] Golf; [] Kayaking; [] Canoeing; [] Swimming in lakes/rivers; [] Horseback riding; [] Local festivals (Which one(s)___ ); [] Local events (Which one(s) ___); [] Arts and Culture (Please specify: __ ); [] Indian Gaming; [] Adventure Parks and Amusement Parks; [] Native American Events; [] Sporting Events (Which one(s): ___ _); [] Bird Watching; [] Hunting; [] ATV Riding; [] Snowmobiling; [] Other

\section{Category 3: Willingness to Participate in Agritourism and Ecotourism}

The following questions are presented in the order given.

1. Is your hospitality facility willing to consider participation in promotional or other arrangements with local commercial service providers in any of the following activities? "Select all that apply."

[] Fishing; [] Ice Fishing; [] Boating; [] Hiking; [] Camping; [] Commercially-operated tours; [] Cross-country skiing; [] Downhill Skiing; [] Biking; [] Golf; [] Kayaking; [] Canoeing; [] Swimming in lakes/rivers; [] Horseback riding; [] Local festivals (Which one(s)____); [] Local events (Which one(s) ___); [] Arts and Culture (Please specify: ___); [] Indian Gaming; [] Adventure Parks and Amusement Parks; [] Native American Events; [] Sporting Events (Which one(s): ___ ); [] Bird Watching; [] Hunting; [] ATV Riding; [] Snowmobiling; [] Other

2. Is your hospitality facility willing to consider participation in promotional or other arrangements with local private land owners for any of the following activities? "Select all that apply."

[] Fishing; [] Ice Fishing; [] Boating; [] Hiking; [] Camping; [] Commercially-operated tours; [] Cross-country skiing; [] Downhill Skiing; [] Biking; [] Golf; [] Kayaking; [] Canoeing; [] Swimming in lakes/rivers; [] Horseback riding; [] Local festivals (Which one(s)____ ); [] Local events (Which one(s) ___ ); [] Arts and Culture (Please specify: __ ); [] Indian Gaming; [] Adventure Parks and Amusement Parks; [] Native American Events; [] Sporting Events (Which one(s): ___ ); [] Bird Watching; [] Hunting; [] ATV Riding; [] Snowmobiling; [] Other 